\title{
Itinerários terapêuticos de usuários que abandonaram o cuidado em Centros de Atenção Psicossocial (Caps-III)
}

\author{
Therapeutic itineraries of users that dropped treatment in \\ Psychosocial Care Centers
}

Noemi Bandeira', Rosana Onocko-Campos ${ }^{\mathbf{1}}$

DOI: $10.1590 / 0103-1104202112807$

\begin{abstract}
RESUMO O objetivo deste estudo foi analisar os itinerários terapêuticos de usuários que abandonaram o tratamento nos Centros de Atenção Psicossocial (Caps) tipo III, identificar os fatores que levaram ao abandono do cuidado, e analisar as percepções dos usuários sobre os serviços e tratamentos propostos. Foi utilizada a metodologia qualitativa, por meio do desenho dos itinerários terapêuticos, elaborados a partir do conteúdo de entrevistas com oito usuários. Os resultados mostraram que, no que concerne à Atenção Básica, existe a manutenção de consultas e medicações, sustentação do vínculo, porém com base em procedimentos médico-centrados. Houve relatos de falta de reconhecimento dos profissionais para a importância do sofrimento psíquico, negligência quanto aos problemas com efeitos colaterais dos medicamentos, e fragmentação entre a saúde mental e a saúde física. Quanto aos Caps, a descontinuidade foi um aspecto mencionado com frequência. Os motivos relacionados ao abandono do cuidado são: falhas no Projeto Terapêutico Singular, falta de vínculo/responsabilização, descaso com relação aos efeitos colaterais de medicações, percepções negativas quanto ao ambiente, falhas na escuta e no momento do encaminhamento. Concluímos que o abandono do cuidado ocorreu principalmente após a estabilização da crise aguda e o encaminhamento para a Atenção Básica, fatores incrementados pelos problemas no Projeto Terapêutico Singular e por falhas na articulação da rede.
\end{abstract}

PALAVRAS-CHAVE Saúde mental. Serviços comunitários de saúde mental. Pesquisa sobre serviços de saúde. Pacientes desistentes do tratamento.

ABSTRACT The aim of this study was to analyze the therapeutic itineraries of users who abandoned treatment in Psychosocial Care Centers (Caps) type III, to identify the factors that led to abandonment and to analyze the perceptions of users about the services and treatments proposed. Qualitative methodology was used through the design of therapeutic itineraries based on the content of interviews with eight users. The results showed that, regarding Primary Care, although the appointments, medications and treatment adherence are maintained, they are based only on medical-centered procedures. Lack of recognition of the importance of psychological distress by professionals, neglect of problems with drug side effects, and fragmentation between mental and physical health was reported. Regarding Caps, a lot of discontinuity was mentioned. The reasons related to the abandonment of care are failures in the Singular Therapeutic Project, lack of bond/responsibility, negligence with side effects of medications, negative perceptions of the Caps environment, listening lack and failures at the time of referral. We concluded that the abandonment of care occurred mainly after the stabilization of the acute crisis and the referral to Primary Care, increased by problems in the Singular Therapeutic Project and failures in the articulation of the care network.

1 Universidade Estadual de Campinas (Unicamp) Campinas (SP), Brasil. noemibany@gmail.com
KEYWORDS Mental health assistance. Community mental health services. Health services research. Patient dropouts. 


\section{Introdução}

O impacto do sofrimento mental na vida das pessoas é alto. Pessoas com problemas mentais apresentam taxas elevadas de incapacidade e mortalidade. Apresentar diagnóstico como os de depressão ou esquizofrenia aumenta a probabilidade de morte prematura de $40 \%$ a $60 \%$ em comparação à população em geral, devido a problemas de saúde que não são devidamente assistidos, como diabetes e hipertensão ${ }^{1}$. Nos países de baixa e média renda, conforme dados da Organização Mundial da Saúde (OMS), cerca de $75 \%$ das pessoas com sofrimento mental não recebem tratamento adequado, resultado de um arraigado subfinanciamento para a promoção de saúde mental2,3.

Algumas pesquisas têm apontado para o gap existente entre as demandas de cuidado e a oferta de tratamento em saúde mental, em termos mundiais ${ }^{4-8}$. No Brasil, embora a política de saúde mental pós-Reforma Psiquiátrica ser bastante avançada e consistente no que tange às diretrizes para os cuidados integrados, há estudos que apontam para dificuldades de continuidade ${ }^{9}$, disparidade de acesso ${ }^{\mathbf{8}, 10}$, além de problemas de equidade ${ }^{11}$ e de integração da rede de atenção ${ }^{\mathbf{1 2}, 13}$.

A Reforma Psiquiátrica enfrenta fragilidades e desafios, tais como: a) graves problemas na gestão dos serviços: b) fragilidade da articulação com a Atenção Básica (AB); c) baixa densidade de articulação das ações intersetoriais; d) ausência de estratégias claras para enfrentar a vulnerabilidade social, e fragilidades na pesquisa no campo da Atenção Psicossociais ${ }^{\mathbf{1 4}}$. Além desses fatores, o subfinanciamento tem sido um problema constante, embora os recursos para serviços comunitários tenham aumentado consideravelmente, superando desde 2006 os valores destinados a hospitais psiquiátricos ${ }^{15}$.

Embora tenha havido uma expansão do número de Centros de Atenção Psicossocial (Caps) ${ }^{16}$, estudos ${ }^{11,17}$ demonstram que não há equidade na implantação dos dispositivos de saúde, nem tampouco na execução das práticas, devido à enorme variação na qualidade, na extensão e na constituição das redes de cuidados em saúde mental, o que gera problemas de acesso e de continuidade do cuidado.

Cabe destacar que capítulos recentes da história da reforma psiquiátrica têm apresentado enormes retrocessos nas políticas de saúde mental. Constatam-se estagnação da expansão dos serviços desde 2011, financiamento inadequado, gerando o desmonte e minando a potência dos serviços já instalados, com falta de investimentos no apoio matricial e na articulação da rede de atenção, além de ausência de transparência na divulgação dos dados sobre saúde mental15. Documentos oficiais do governo, como a Portaria ${ }^{0} 3.588$ de dezembro de $2017^{18}$ e a Nota Técnica $n^{\circ} 11$, de fevereiro de $2019^{19}$, reabriram a possibilidade de retorno de serviços pautados pela lógica biomédica, já ultrapassada, financiados pelo governo federal, como os ambulatórios especializados, os hospitais monovalentes e comunidades terapêuticas. Essas medidas resultam em fragmentação e prejuízo da integralidade e da continuidade do cuidado, indo na contramão da ampliação da rede comunitária de serviços de saúde mental, conforme recomendações dadas pela OMS e pelas evidências científicas apontadas nas pesquisas de âmbito mundial ${ }^{20}$.

É importante destacar que a integração entre as ações e os serviços deve ser o foco das linhas de cuidado e projetos terapêuticos. Essa orientação concerne diretamente à integração entre serviços especializados e a atenção primária, estando de acordo com as recomendações da OMS ${ }^{21}$, e com estudos que enfatizam a importância da atenção primária na saúde mental5,10,22.

Este estudo derivou de uma pesquisa multicêntrica, denominada 'Inquérito sobre o acesso a partir da Atenção Básica, o funcionamento e a utilização da atenção especializada para quatro condições traçadoras em quatro grandes cidades brasileiras' chamada AcesSUS. Essa pesquisa transversal constituiu-se como um censo de usuários de serviços de saúde 
mental (Caps). Após a fase quantitativa, surgiu a necessidade de investigar as perdas da amostragem, em termos qualitativos.

Desse modo, teve início uma investigação sobre os usuários que foram inseridos nos Caps tipo III de Campinas no período que antecedeu a coleta de dados, e que não foram localizados no momento da pesquisa AcesSUS, denominados casos-perda. Após a constatação de que muitos eram casos de abandono ou de não adesão ao tratamento nos Caps, a intenção foi compreender a experiência dos sujeitos na busca por cuidado em saúde mental.

Portanto, o objetivo desse estudo foi analisar os itinerários terapêuticos de usuários que abandonaram o tratamento nos Caps III, identificar os fatores que levaram ao abandono do cuidado, e analisar as percepções dos usuários sobre os serviços e tratamentos propostos.

\section{Metodologia}

Trata-se de pesquisa qualitativa, utilizando o desenho dos itinerários terapêuticos, a partir do conteúdo de entrevistas abertas, em profundidade, realizadas com oito pessoas quatro mulheres e quatro homens. A escolha dos sujeitos foi feita a partir das perdas da amostragem da pesquisa AcesSUS.

A pesquisa AcesSUS detectou grande número de usuários (41,8\%) que, embora estivessem cadastrados nos serviços, não foram localizados no momento do censo nos Caps. Os resultados de uma busca pelos prontuários nos seis Caps III para adultos disponíveis no município mostraram que o abandono do tratamento foi a causa predominante da não localização desses usuários.

Após esse levantamento, foi empreendida uma busca por telefone e por endereço dos casos-perda. Foram buscadas 72 pessoas, das quais 48 não foram localizadas. Das outras 24, houve quatro recusas e 20 foram procuradas pelo endereço. Ao final, foram obtidas oito entrevistas, que foram realizadas nos domicílios, após a assinatura do Termo de Consentimento Livre e Esclarecido. Essas entrevistas foram gravadas e transcritas.

O estudo foi submetido e aprovado pelo Comitê de Ética da Faculdade de Ciências Médicas da Universidade Estadual de Campinas, por meio do Parecer Técnico $\mathrm{n}^{\mathrm{o}}$ 2.225.109. Foi realizado cumprindo normas e diretrizes brasileiras de regulamentação de pesquisas envolvendo seres humanos (Resolução CNS nº 466/2012). E para garantir o anonimato dos sujeitos, todos os nomes utilizados na descrição dos resultados são fictícios.

O primeiro passo do processo analítico foi o desenho dos itinerários, que permite $\mathrm{o}$ acesso à experiência vivida ${ }^{23}$, tendo em vista a dimensão espacial, isto é, os lugares percorridos e a dimensão temporal, a ordem das buscas. A seguir, a figura 1 apresenta os vetores que ilustram os retornos e encaminhamentos. 
Figura 1. Ilustração dos itinerários

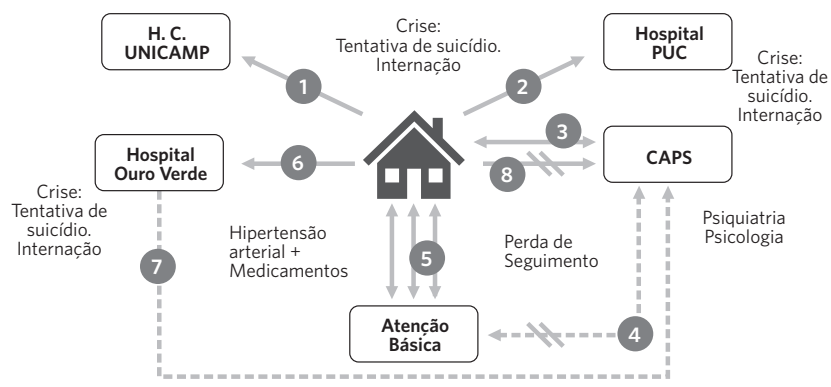

Itinerário de Nádia, 50 anos

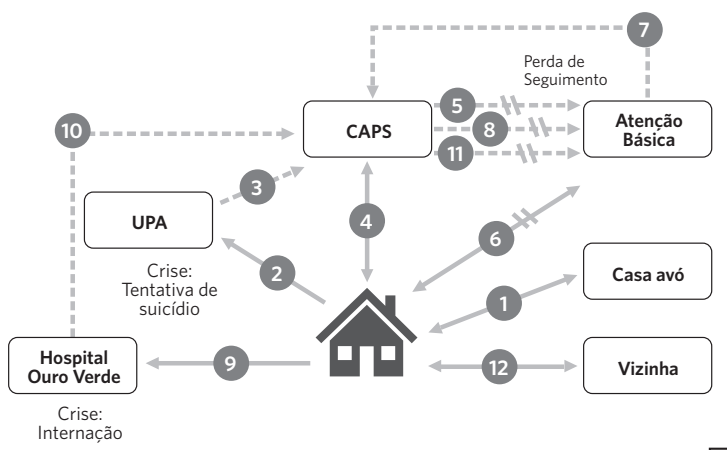

Itinerário de Jessica, 30 anos

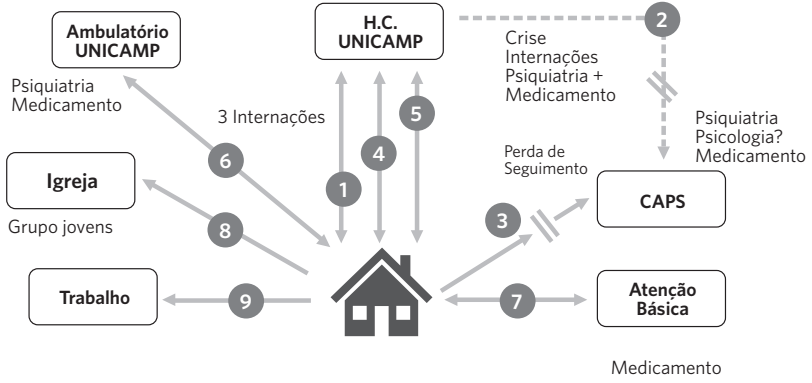

Itinerário de Murilo, 26 anos

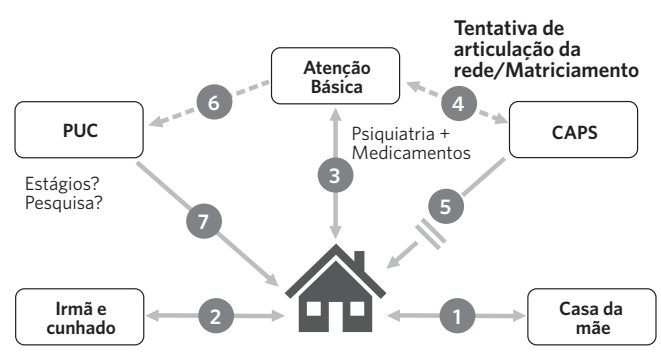

Itinerário de Miguel, 21 anos

Fonte: Elaboração própria. Baseado em Silva et al.24.

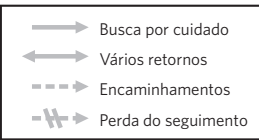

$\longleftrightarrow$ Vários retornos

It $\rightarrow$ Perda do segu
Em seguida, foi utilizado uma versão do 'Quadro Analítico da Trajetória Assistencial', desenvolvido por Silva et al. ${ }^{24}$ para análise de cada caso, contendo os locais buscados, as situações em que esses serviços foram acessados, os recursos utilizados na assistência prestada, a resolutividade, e a análise de cada caso com cada serviço. Definimos resolutividade não como solução final dos problemas psíquicos, mas como avaliação da tríade: responsabilização/vínculo, integralidade e continuidade do cuidado. $\mathrm{O}$ quadro 1 inserido aqui traz um exemplo.

Quadro 1. Análise dos Itinerários - Caso J4

\begin{tabular}{|c|c|c|c|c|c|}
\hline $\begin{array}{l}\text { Serviços de saúde } \\
\text { percorridos }\end{array}$ & Quando? & $\begin{array}{l}\text { Recursos } \\
\text { Utilizados }\end{array}$ & Resolutividade & Observações & Análise \\
\hline UPA & $\begin{array}{l}\text { Crise - Tentati- } \\
\text { va suicídio }\end{array}$ & Medicação & Média & $\begin{array}{l}\text { Desempenho como esperado para } \\
\text { um serviço de emergência. }\end{array}$ & $\begin{array}{l}\text { Apesar de ser emergência, houve } \\
\text { encaminhamento para o Caps. }\end{array}$ \\
\hline CAPS & $\begin{array}{l}\text { Crise } \\
\text { Intervenção } \\
\text { por período até } \\
\text { estabilização } \\
\text { da ansiedade } \\
\text { Diagnóstico de } \\
\text { Depressão + } \\
\text { Borderline }\end{array}$ & $\begin{array}{l}\text { Consultas } \\
\text { psiquiátri- } \\
\text { cas; Psico- } \\
\text { logia Medi- } \\
\text { camentos }\end{array}$ & $\begin{array}{l}\text { Baixa, falta: } \\
\text { vínculo, in- } \\
\text { tegralidade. } \\
\text { Perda do se- } \\
\text { guimento após } \\
\text { encaminhar } \\
\text { para AB }\end{array}$ & $\begin{array}{l}\text { A usuária necessita acompanha- } \\
\text { mento psicológico constante, seus } \\
\text { conflitos emocionais não parecem } \\
\text { ter sido resolvidos. Dúvidas sobre o } \\
\text { Projeto Terapêutico Singular (PTS). } \\
\text { Será que foi considerado o alto risco } \\
\text { de suicídio? Histórico de violência } \\
\text { doméstica, uso de álcool e proble- } \\
\text { mas com saúde mental na família. }\end{array}$ & $\begin{array}{l}\text { Apesar de ser resolutivo no período } \\
\text { mais crítico, após o encaminha- } \\
\text { mento, houve perda do seguimento, } \\
\text { usuária não deu continuidade na } \\
\text { AB. Vários retornos e uma interna- } \\
\text { ção por tentativa de suicídio. } \\
\text { Provavelmente falha na construção } \\
\text { do PTS, na escuta clínica com as- } \\
\text { pectos negligenciados. }\end{array}$ \\
\hline
\end{tabular}


Quadro 1. (cont.)

\begin{tabular}{|c|c|c|c|c|c|}
\hline $\begin{array}{l}\text { Serviços de saúde } \\
\text { percorridos }\end{array}$ & Quando? & $\begin{array}{l}\text { Recursos } \\
\text { Utilizados }\end{array}$ & Resolutividade & Observações & Análise \\
\hline UBS & $\begin{array}{l}\text { Fase de estabi- } \\
\text { lização + medi- } \\
\text { camentos }\end{array}$ & $\begin{array}{l}\text { Consultas } \\
\text { c/ clínico } \\
\text { + medi- } \\
\text { camentos } \\
\text { (renovação } \\
\text { da receita) } \\
\text { + tentativa } \\
\text { de grupos } \\
\text { psicotera- } \\
\text { pêuticos }\end{array}$ & $\begin{array}{l}\text { Baixa } \\
\text { Perda do se- } \\
\text { guimento } \\
\text { Descontinui- } \\
\text { dade da medi- } \\
\text { cação }\end{array}$ & $\begin{array}{l}\text { Dificuldade de vínculo. Tendência } \\
\text { ao isolamento e passagens ao ato } \\
\text { como Cutting e tentativa de suicídio. }\end{array}$ & $\begin{array}{l}\text { Foi ofertado atendimento psicote- } \\
\text { rapêutico individual e em grupos. } \\
\text { A usuária não consegue um bom } \\
\text { vínculo com psicólogos da AB. Mas } \\
\text { sente e sabe da necessidade de } \\
\text { acompanhamento psicológico. PTS } \\
\text { = busca ativa? Problemas na escuta } \\
\text { clínica? }\end{array}$ \\
\hline HOSPITAL GERAL & $\begin{array}{l}\text { Crise - Ten- } \\
\text { tativa suicídio } \\
\text { Internação }\end{array}$ & $\begin{array}{l}\text { Internação } \\
\text { Consultas } \\
\text { Medica- } \\
\text { mentos }\end{array}$ & Média & & $\begin{array}{l}\text { Internação curta, com estabilização } \\
\text { da crise. Encaminhamento para } \\
\text { Caps. }\end{array}$ \\
\hline
\end{tabular}

Fonte: Elaboração própria. Adaptado de Silva et al24.

Os resultados foram agrupados em três blocos: o primeiro sintetiza as passagens de cada usuário pela $\mathrm{AB}$; o segundo aborda, de forma mais detalhada, as buscas e percepções dos sujeitos sobre o Caps; e o terceiro resume as passagens e questões advindas das internações psiquiátricas externas ao Caps.

\section{Resultados e discussão}

\section{Os percursos na Atenção Básica}

Em quase todos os itinerários aparecem reiteradas buscas por cuidado em saúde mental na $A B$, seja por demanda espontânea, seja por encaminhamento do Caps. Essas buscas ocorreram mormente após um período de crise aguda e de uma fase de estabilização. Apenas uma entrevistada não cita a $\mathrm{AB}$ em seu itinerário.

No que concerne à resolutividade da $\mathrm{AB}$ no cuidado em saúde mental, apenas em um caso foi possível inferir alta resolutividade. Esse usuário afirma estar bem, considera a unidade como referência para o seu cuidado em saúde mental, e mantém vínculo. A Unidade Básica de Saúde (UBS) o encaminha para o Caps nos momentos de crise e faz acompanhamento com medicamentos. Ele afirma: "Aqui no posto, se tivesse psicólogo eu iria. [...]. Mas tô bem agora. No posto, o atendimento é bom. Se eu tivesse um problema, eu iria no posto" (Eduardo).

Os casos de média resolutividade trazem pontos positivos e negativos. Os positivos dizem respeito à manutenção de consultas e medicações e uma certa estabilidade, quando a pessoa não abandona o uso dos medicamentos.

Eu busco meu remédio na Unicamp e no posto de saúde [...]. Eu tô correndo atrás de passar por psicóloga, mas tá difícil. Aqui o posto não tem mais psicóloga. (Murilo).

Esses atendimentos funcionam, sustentam o vínculo, mas são baseados em procedimentos médico-centrados. Com relação a isso, outros estudos ${ }^{25,26}$ alertam para o uso de psicofármacos por longos períodos, com pouca avaliação e pouca informação ao usuário sobre a duração e o motivo do uso dos medicamentos.

No caso de isolamento social com dificuldade de sair de casa, torna-se crucial outra abordagem, um atendimento que vá até o domicílio, 
e nesse ponto, as entrevistas mostraram que a $\mathrm{AB}$ apresenta fragilidades. Um exemplo é o caso de Miguel, que vive isolado em casa:

Vou a cada dois meses, ou um mês e meio, se não me engano. A médica conversa, falo pra ela que tô fazendo os exercícios e ela passa os medicamentos, anota, passa a receita de novo, porque pode vencer, pode esgotar na hora, depois ela me pesa, a única coisa que me interessa mesmo é a pesagem. O povo do centro de saúde não vem aqui, eu vou lá no dia que marca, com a psiquiatra. (Miguel).

Nos casos de baixa resolutividade, os desafios são maiores. Nessas situações, há constantemente perda do seguimento e descontinuidade do cuidado, e até mesmo da medicação. A AB responde às demandas do usuário com consultas e medicamentos, o que não surte efeito, gera frustração e descrença. Percepções como falta de acolhimento por parte dos profissionais para o sofrimento psíquico, e também negligência quanto aos problemas com efeitos colaterais dos medicamentos são questões que emergem das narrativas.

Eu fui ao Caps depois fui ao posto de saúde [...] Médico, faz dias, hein? Desses médicos aí de...? (psiquiatras), não fui... faz tempo já. Eu queria um tratamento pra mim dormir. Então eu preciso, mas hoje em dia é tão difícil! [...] Mas aí eu falo: ah, vai no médico, você fica lá na fila, passando raiva, vê pessoa morrendo na sua frente lá, por isso que eu também não vou, viu, porque tá um caos tá esse negócio da saúde aí. (Augusto).

Eu parei de tomar aqueles remédios... uns que era de dormir, o meu coração acelerava demais, eu acordava... era calmante, né? Não tomo mais esses medicamentos. O que eu sentia, minha blusa ficava... palpitando, eu digo: vou desmaiar... Aí minha respiração voltava, aquela dor no peito... esse negócio assim, sabe? Não cheguei a discutir com o médico. (Augusto).

Os entrevistados mostram que os atendimentos recebidos na $\mathrm{AB}$ ainda são marcados por uma divisão - isto é, a saúde mental apartada dos problemas de clínica geral. Relatam falta de integralidade, ou seja, ausência de um Projeto Terapêutico Singular (PTS) que considere as demandas do usuário, o que resulta em abandono do cuidado e descontinuidade sem orientação no uso de medicamentos, mesmo quando a pessoa não está se sentindo bem. A falta de apoio social e psicoterápico é apontado por outro estudo como fator que leva à medicalização ${ }^{26}$.

Fui ao posto de saúde. Igual hoje... eu tenho consulta já há uns dois anos e não me chamam... então desisti, você tá entendendo? [...] Eu tomei muitos remédios que eu acho que não era pra eu ter tomado e acarretou outros problemas. Hoje eu tenho uma gastrite nervosa que me prejudica. $\mathrm{Na}$ verdade, até hoje eu sinto aquela vontade de não viver, entendeu? Eu sinto esses problemas ainda... mas fico pra mim, né? Assim mesmo... (Augusto).

Outro problema é a falta de adesão do usuário ao tratamento psicológico. Em algumas unidades não há essa oferta, e naquelas em que esse serviço é ofertado há pouca adesão. Há situações em que usuário não percebe a UBS como local para cuidar de sua saúde mental, embora já tenha frequentado psicólogo por algum tempo. A necessidade de atendimento psicológico é reconhecida pelas próprias pessoas, portanto infere-se que a manutenção desse cuidado evitaria situações agudas.

Renovo a receita no postinho. Tem o psicólogo e o psiquiatra. Na realidade, esses dois meses eu não fui, agora tenho que marcar pra de ir de novo. Só tô renovando a receita, todo mês, com o clínico. Eu deixo lá e ela... só que ela já me falou que eu tenho de marcar com o psicólogo, o psiquiatra. $\mathrm{Na}$ realidade, é mais por descuido meu, não que era pra mim parar... (Jéssica).

Mas eu tenho de passar no psicólogo. Eu preciso passar, porque o psiquiatra falou: 'Você tem de ir no psicólogo'. Pediram pra eu fazer acompanhamento com o psicólogo no posto. Tem psicólogo aqui na 
UBS. Mas eu não conheço, as meninas falaram que ele é ruim, que é muito ruim, por isso que eu não fui ainda. Não fui lá ver... Porque assim, eu não tenho muita paciência, sabe... (Nádia).

É imprescindível repensar a forma como esses atendimentos são ofertados, com caráter ambulatorial, de escuta individualizada, em horários agendados em que se espera que a pessoa compareça. Em alguns casos, há necessidade de uma busca ativa, e até de outra tecnologia de atenção em saúde mental da qual a $\mathrm{AB}$ não dispõe, como, por exemplo, acompanhamento terapêutico. Especificamente nesses casos, para além da oferta de atendimento individual e em grupos, há demanda por outras formas de escuta clínica, qualificada, fora dos padrões da clínica tradicional em consultório, conforme já apontado por Onocko Campos \& Gama ${ }^{27}$.

\section{Idas e voltas ao Caps}

Todos os itinerários construídos revelam passagem pelo Caps. Mesmo que a pessoa tenha sido apenas encaminhada e nunca tenha frequentado, a equipe tentou uma proposta de cuidado. $\mathrm{O}$ acolhimento é bem avaliado, e de maneira geral, a equipe é elogiada. No que tange à resolutividade, considerando que todos os entrevistados abandonaram o cuidado no Caps, há problemas no estabelecimento do vínculo.

Acho que o Caps é uma internação, um centro de associação psiquiátrica. Não fui nem conhecer, nem sequer vi como é. Vieram um povo, psiquiatra nessa casa, depois passou a vir gente do Caps e depois veio gente da PUC e até agora tá assim. Ele veio ver o que tava acontecendo comigo, qual o tipo de problema que eu tenho. Eu não sei quem chamou, não me disseram nada, eles vieram. A primeira vez que vieram eu não tive mais como saber de onde eles saíram. Aí começou a vir um monte de gente pra cá, gente diferente, às vezes mudando um de lado pra cá, de um lado pro outro, aleatoriamente... (Miguel).
Essa é a única fala de Miguel, de 21 anos, citando o Caps. Ele foi diagnosticado com esquizofrenia, e permanece em casa o tempo todo, com um isolamento social importante, sem atividade de trabalho, estudo, lazer, esporte, sem relacionamentos sociais fora de casa, vive na dependência total da cuidadora. Percebe-se que ele não consegue distinguir o movimento da equipe, nem entender claramente de onde vinham aqueles profissionais. Não demonstra ter-se vinculado a nenhum deles, pois sequer lembra quem são. Além disso, recusou-se a ir até ao Caps. Tudo leva a crer que não houve vínculo efetivo com o Caps. Nesse caso, apesar da tentativa de atendimento domiciliar, o Caps falhou na construção de um PTS que considerasse as possibilidades e os desafios do caso, como a habilidade artística do usuário, seu gosto por jogos eletrônicos e por séries de TV. O foco do atendimento foi na psiquiatria e nos medicamentos. Houve pouco vínculo/responsabilização no caso, que foi entregue para $\mathrm{AB}$, onde ele consegue ao menos comparecer às consultas psiquiátricas e trocar receitas.

Fui umas cinco vezes ou mais... la à consulta, ficava lá, conversava com a médica. Tomei injeção. Não cheguei a participar das atividades, passei sim pela psicóloga. ... Até que um dia eu fui e tinha... muita gente, eu voltei pra trás. Eu ficava vendo aquelas pessoas, e aquilo tava me deixando estressado, de ver aquelas pessoas transitando. Eu não tava aguentando, às vezes chegava uma pessoa, dava vontade de eu mesmo pegar e... de agredir. Eu não fui mais, eles ficam bravos que eu não fui, mas eu falei: eu tô bem, então não vou. Eu queria um tratamento pra dormir. Então, eu preciso, mas hoje em dia é tão difícil! (Augusto).

Augusto, de 60 anos de idade, procurou o Caps após uma crise de ansiedade com períodos de agressividade e de depressão. No auge do sofrimento, o cuidado com psiquiatra e medicamentos amenizou a crise, mas não criou vínculo para um tratamento adequado da ansiedade. $\mathrm{O}$ fato de o usuário não apresentar 
uma crise psicótica possivelmente levou à desvalorização dos seus sintomas. O ambiente do Caps é percebido pelo usuário como não acolhedor, ameaçador, e lá ele sentia vontade de agredir as pessoas.

Augusto foi medicado e aconselhado a procurar atendimento psicológico na $\mathrm{AB}$, porque, segundo o médico, não precisava frequentar o serviço continuamente. Mas ele não foi para a UBS, e perdeu-se a continuidade do cuidado. Em pouco tempo, o usuário descontinuou o uso de medicamentos por conta própria, pois, segundo ele, ele piorava quando tomava os remédios. Sentia muitos efeitos colaterais, e essa queixa foi desconsiderada pelos profissionais, tanto do Caps quanto da UBS. Por várias vezes, procurou a UBS para tratar sintomas físicos, mas esse expediente tem mostrado pouca resolutividade, pois a resposta vem em forma de medicamentos para os sintomas, com mais efeitos colaterais indesejáveis. Procurou também um atendimento psiquiátrico particular, mas, por falta de condições financeiras, interrompeu o tratamento. No momento da entrevista, ele ignorava o fato de que, na sua condição, poderia ser necessário um acompanhamento psicológico mais longo.

Nádia, tem 50 anos, e no seu caso parece ter havido falha na articulação dos serviços. O Caps encaminhou, mas a usuária não se vinculou à $\mathrm{AB}$, e ficou no gap entre o serviço especializado para casos graves, no qual ele não se encaixou, e a $\mathrm{AB}$, onde seu sofrimento psíquico não foi devidamente reconhecido.

O ano passado eu fui algumas vezes no Caps, mas acho que foi mais pelo ano retrasado. Não lembro muito bem, a equipe, eles queriam que eu ficasse lá, mas meus filhos não deixaram, entendeu? Porque, assim, tava muito misturado, pessoas com drogas, pessoas mais doidas do que eu, ainda! Entendeu? Então, aquilo me deixava impressionada, de ver aquelas pessoas assim, eu ficava... eu ficava meia birutando também. (Nádia).

Para Nádia, o encaminhamento para o Caps se deu após duas internações por tentativa de suicídio. A equipe insistia em internação no Caps, mas a família não concordou. Durante o tempo que frequentou, houve estabilização do quadro, mesmo sem internação. O Caps tentou outras intervenções, porém a usuária não se sentia bem no ambiente. Após o encaminhamento para a UBS, houve descontinuidade do cuidado e do uso de medicamentos. Nádia demanda cuidado sistematizado, como prevenção para evitar a crise. Após o abandono do cuidado no Caps, houve duas novas tentativas de suicídio com internações no hospital geral.

Eu tinha até que voltar para o Caps, o Ouro Verde [Hospital] entrou em contato, passando, né, o que tinha acontecido. E eu não fui. Inclusive, eu tenho que voltar a fazer o tratamento, porque eu tô sem o remédio, eu tô com os calmantes aí, eles até escondem de mim, meu marido, meus filhos até escondem, porque é uma coisa assim... como que eu vou te explicar... eu não posso passar nervoso. Se eu passar nervoso hoje, é com três dias, certinho. Em três dias ela me derruba [a crise]. Aíjá acaba a minha vida, sabe? (Nádia).

Nádia frequenta a $\mathrm{AB}$, faz acompanhamento para hipertensão arterial e retira receita e medicamentos psiquiátricos, mas não se vincula a um tratamento psicológico, embora haja essa oferta na UBS. É possível que o vínculo prejudicado com psicólogos do Caps tenha contribuído para o abandono. Ela critica a escuta psicológica que lhe foi ofertada:

Todas as vezes que eu fui, eu estava mal. Nenhum profissional nunca me disse para procurar um psicólogo e continuar o acompanhamento quando eu estivesse bem. Talvez se eu fosse assim, quando estou bem, eu tivesse outra impressão sobre o psicólogo e conseguisse falar. Todas as vezes que fui no psicólogo, eles ficavam fazendo perguntas sobre meu passado, cavucando o passado, assim: 'Por que seu filho morreu? O que deu nele? Qual a doença? Você cuidava bem dele?'. Eu até avancei pra agredir uma médica que ficou fazendo essas perguntas quando eu tava em crise. (Nádia). 
$\mathrm{O}$ atendimento psicológico foi sempre ofertado em momentos de crise, quando havia muita resistência. A usuária mostra-se surpresa quando questionada se já foi orientada a buscar psicoterapia para cuidar dos aspectos emocionais em momentos em que estava estabilizada Nádia traz longo histórico de violência familiar e angustiantes conflitos emocionais que não foram devidamente abordados pelos profissionais que a atenderam.

Jéssica é uma jovem de 30 anos, que procurou o Caps após passar pelo hospital geral, devido a uma tentativa de suicídio. Apesar de resolutivo no período mais crítico, houve perda do seguimento após o encaminhamento para a AB. Jéssica interrompeu o uso dos medicamentos por conta própria, não retornando para a renovação da receita na UBS.

Foi numa época que eu tava bem mais ruim, porque eu já comecei... aí todo mundo ficava falando que era invenção, que era pra chamar a atenção. Aí eu fui me sentindo cada vez mais mal. Aí eu tentei me enforcar. Aífoi a primeira vez que eu fui pro Caps, porque fui por duas vezes lá. Passei um tempo lá, depois me mandaram ir pro postinho, porque lá é de pessoas mais graves, né? Aí parei de passar lá. Só que aí eu começo, aí passa um tempo, aí, 'ai, tô boa!', aí, paro de ir, aí comecei a ficar ruim de novo, me mandaram pro Caps de novo, agora me mandaram pro postinho de novo. (Jéssica).

Jéssica afirma que havia melhorado quando foi encaminhada para a $\mathrm{AB}$, e que seu quadro não exigia frequência ao Caps. A narrativa da usuária sugere necessidade de acompanhamento psicológico constante, pois ela continua com os sintomas de Cutting e isolamentos em seu quarto, por períodos ou por dias inteiros. Jéssica também traz longo histórico de violência doméstica, abuso sexual e problemas de saúde mental e uso de álcool na família. Houve novas crises e retorno ao Caps.

A outra vez foi nesse ano passado, ou retrasado, que eu fazia cortes, só que, na realidade, eu nunca fiz pra me matar, era só pra machucar. Só que aí, os da perna, começou a fazer mais fundos e aí, uma vez, eu tive uma crise, me levaram pro hospital e aí me mandaram pro Caps de novo. (Jéssica).

Provavelmente houve falha na construção do PTS e na escuta clínica. Jéssica reclama da escuta do psicólogo no Caps, porque ela tem muita dificuldade de falar, é bem fechada, e o profissional simplesmente lhe pedia pra falar e ficava em silêncio, esperando. A angústia era insuportável, e ela abandonou o tratamento.

Quando eu ia no Caps era pior ainda, porque aqui eles ainda conversam. No Caps, ele só sentava e falava: 'fala!'. E ele ficava olhando assim e ele ... deixava a gente falar, sabe? E eu não sou assim, e acho que assim é pior... Então eu deixo de ir mais por causa disso... (Jéssica).

Camila tem 31 anos, e faz sua inserção no Caps de forma ambulatorial. Elogia o atendimento, percebe o Caps como local de acolhimento para momentos de crise. No entanto, nota-se a vinculação a apenas um profissional, o psiquiatra que atendeu na primeira crise.

Na segunda vez, fui sozinha no Caps, eu mesma fui direto no Caps, cheguei lá e falei que não tava bem. Atividades no Caps, em conjunto assim, não fiz não. Então teve o médico, essa psicóloga que fui umas poucas vezes e depois eu não quis ir mais. E só. Sobre o pessoal que trabalhava lá, sempre fui bem tratada, eu chegava, todo mundo atencioso comigo. E eu achava o psiquiatra totalmente diferente, um cara aberto a tudo, escutava bastante, então tive grande empatia com ele. (Camila).

O percurso de Camila foi diferente, pois ela não passou pela $\mathrm{AB}$. Ela vem encaminhada pelo psiquiatra que a atendeu em uma internação no Hospital Universitário após uma crise psicótica. Após um período de estabilização, com medicamentos e consultas psiquiátricas, Camila adquiriu boa percepção de sua condição e procurou por acompanhamento psicológico e psiquiátrico ambulatorial. Tentou atendimento psicanalítico particular, criou 
vínculo com a analista e abandonou o Caps. Apesar da descontinuidade, a usuária reconhece o serviço como referência, caso necessite. Tentou vínculo com psicóloga no Caps, mas não conseguiu. Também nesse caso, a usuária aponta para problemas na escuta psicológica no Caps, que dificultaram seu vínculo e o seguimento no serviço.

No Caps, até tentei com uma psicóloga na época, mas não tive empatia com ela. Não lembro nem o nome dela. Ela ficava o tempo todo martelando que eu não era paciente de Caps [...] Eu lembro bastante que a conversa era só essa. Então, não teve uma preocupação assim com o que eu queria no momento, que era descobrir o que tava acontecendo. (Camila).

Nesse caso, a usuária também descontinuou o uso de medicamentos, por sua própria conta. Mesmo após novas crises, nota-se que Camila tem recursos, como bom apoio familiar, rede social ampla e recurso financeiro para buscar cuidado fora do Caps.

Manuela, de 51 anos, também relata perda do seguimento e descontinuidade no uso de medicamentos:

Não, não gostava de participar de atividades, não gostava, não queria, nunca participei de nenhuma atividade. Cheguei a ir um período, mas ia mesmo pra tomar o medicamento, depois não voltava mais. Eu não achava que tinha necessidade de eu ir, estar lá toda semana, né? Ah, porque eu achava que aquele ambiente não era pra mim, que eu não tava ruim naquele ponto de estar lá com aquelas pessoas, entendeu? Com problemas bem mais sérios, né, então, eu não me sentia bem de estar lá com eles. Então eu não ia. (...) Remédio, quando preciso, vou ao Caps, mas tá em falta, se eu quiser, preciso comprar. Faz uns três meses que eu parei. É injeção, tem de ser no Caps. (Manuela).

Manuela chegou ao Caps após recomendação da psicóloga da $\mathrm{AB}$, com crise psicótica. $\mathrm{O}$ atendimento foi acessível e bem estruturado, conteve a crise. Consideramos que a resolutividade foi média, porque ela obteve uma estabilização significativa. No entanto, ela não se identifica com os demais usuários e percebe o ambiente como perturbador.

Inferimos que houve falhas no PTS, pois as necessidades sociais e profissionais não foram ouvidas, como falta de apoio social, sensação de solidão, falta de perspectivas profissionais e de independência financeira. Os problemas que Manuela aponta como cruciais são principalmente a falta que ela sente do trabalho fora de casa e a dependência financeira do marido. Interrompe a medicação quando se sente bem. Há perda do seguimento no Caps, mas fica mantido o vínculo com a UBS. Talvez essa usuária se beneficiasse da inclusão em alguma oficina de geração de renda, por exemplo. No entanto, não parece ter havido nenhuma tentativa nesse sentido.

Eu sinto falta de amigas, né, pra ser sincera, porque assim, não tenho. [...] Não frequento nenhum grupo, nem religioso [...] Fico mais aqui, cuido da casa, dos filhos [...] Foi difícil pra mim parar de trabalhar. Sinto falta de ter o meu dinheiro, de ser mais independente, hoje eu dependo muito, né? Por mais que você não queira, você depende muito do dinheiro do marido. Acho que foi isso também, sabia? (Manuela).

Murilo, de 26 anos, não sente qualquer atrativo pelo Caps. Depois da crise, percebe o ambiente como abandonado, pouco acolhedor, malcuidado. Se não fosse pelo ambiente físico, os profissionais conseguiriam bom vínculo, pois Murilo os elogia, mas pesa também o fato de ele não se identificar com os demais usuários do Caps.

Quando cheguei no Caps, eu já tive uma visão muito negativa daquele lugar. Não só pelo fato de ser tudo fechado, porque ninguém gosta, nem animal gosta de ficar preso, entendeu? Eu sei que às vezes tem de ter a contenção, senão a pessoa pode se machucar. Mas ali, você chega ali, o Caps, você chega lá é uma pessoa deitada... - assim, tudo bem, eu respeito! A pessoa tá doente, mas não 
tem uma atenção [...] o lugar em si, não que era um lugar ruim, mas é que entrando ali, você tem a impressão que tá meio abandonado, vamos dizer, sabe? O prefeito, ele virou as costas para aquilo ali. Os profissionais são bons, a estrutura é que não é boa, os mantimentos, talvez, entendeu? Acho que o dinheiro que era pra investir ali, eles investiam... talvez... não sei como funciona a burocracia ali, sou leigo nessa área. (Murilo).

Nesse caso, a resolutividade do Caps foi baixa, houve perda do seguimento e descontinuidade do uso de medicamentos, situações de novas crises e internações. Murilo veio para o Caps após uma internação no HC Unicamp, em situação de crise psicótica.

O Caps, eles são assim, você vai lá, você fica lá, eles dão o remédio, você fica dopado, sai, eles não estão nem aí. Não fala que o cara tem um tratamento... Ah, sim, no Caps tinha grupo, eles falavam pra ir lá e participar do grupo, tinha isso daí, fui uma vez. Não, porque daí eu... Ah sim, lembrei! Eles me deram um remédio que eu não me adaptei, aí não fui mais lá. (Eduardo).

Eduardo tem 52 anos, e foi encaminhado ao Caps pela $\mathrm{AB}$, com crises de pânico e depressão, após ser vítima de um assalto enquanto trabalhava de cobrador de ônibus. Sua condição melhorou após consultas psiquiátricas e uso de medicamentos. Ele teve problemas com efeitos dos medicamentos, afirma ter ficado dopado e que a equipe não considerou esse problema, razão do abandono. O usuário parece demandar atendimento psicológico. Houve encaminhamento para ambulatório de psicoterapia na PUC, que ele chegou a frequentar por pouco tempo, mas também abandonou. Eduardo não conseguia sair de casa sozinho, seu pai o acompanhava aos atendimentos. Após a morte do pai, ficou sem essa retaguarda e abandonou o cuidado. Houve perda do seguimento psicológico e descontinuidade no uso de medicamentos. No entanto, Eduardo mantém bom vínculo com a UBS e, por meio de outros recursos, como a religião e o trabalho, está conseguindo manter-se estável. "Aqui no posto, se tivesse psicólogo, eu iria. Cheguei a fazer atendimento psicológico na PUC, mas parei de ir" (Eduardo).

\section{Internações em hospital geral}

Dos oito casos estudados, dois iniciaram o percurso na saúde mental por meio de internação psiquiátrica, e um terceiro já vinha sendo acompanhado na $\mathrm{AB}$, mas foi encaminhado ao Caps depois de uma internação no hospital geral, por tentativa de suicídio. Um dos casos passou pela emergência no hospital, mas a família não permitiu a internação, apesar dos esforços da equipe médica para isso. É importante assinalar que, mesmo após a implantação dos Caps, muitos usuários iniciam seus percursos na saúde mental após uma internação ${ }^{23}$. As internações nos hospitais gerais ocorreram em momentos de crise, centradas no uso de medicamentos, sem construção de rede, sem PTS e sem continuidade no cuidado. Portanto, em termos de continuidade e integralidade a resolutividade é baixa, mas é considerada alta no momento da crise. Há que considerar como ponto positivo o fato de que em todos os casos houve o encaminhamento para o Caps. Em um caso, o usuário foi encaminhado para o Ambulatório de Psiquiatria da Unicamp, onde se vinculou, pois o ambiente, embora hospitalar, lhe pareceu mais acolhedor e organizado do que o Caps.

Na verdade, eu fiquei internado três vezes no hospital da Unicamp, na psiquiatria, na enfermaria da Unicamp. [...] A Unicamp é totalmente diferente! Você chega ali, você tem um tratamento bom. Até o alimento, na Unicamp dá de dez a zero no Caps [...] Eu não quero voltar nunca mais para o hospital, porque é horrível você ficar amarrado, você ficar fechado num lugar. Horrivel que eu falo é porque o tratamento é bom, chega a ser excelente, é ótimo, os profissionais são bons, o hospital é bom, mas uma pessoa, ninguém gosta de ficar... se você ficar 
um dia parado dentro de um quarto, de um cômodo, você já começa a ficar incomodado. (Murilo).

\section{Conclusões}

Apesar de médico-centrado, o atendimento na UBS é bem avaliado pelos usuários, e tem resolutividade em manter certa estabilidade quando a pessoa não abandona o uso dos medicamentos. Em sua maioria, os usuários não percebem a UBS como local para cuidar de sua saúde mental de forma mais ampla, ou seja, para além das consultas e da prescrição de medicamentos.

Emergem das narrativas problemas como falta de acolhimento para com o sofrimento psíquico, negligência quanto aos efeitos colaterais dos medicamentos, e fragmentação entre saúde física e saúde mental. A consequência é a perda do seguimento, descontinuidade no uso de medicamentos sem orientação, e eclosão de crises, como, por exemplo, tentativas de suicídio.

Considerando que a rede de Campinas oferece atendimentos psicológicos na $\mathrm{AB}$ um recurso ausente na maioria das cidades do País -, é imprescindível repensar a forma como os atendimentos psicológicos são ofertados: Os resultados apontaram para um caráter ambulatorial burocratizado, calcado na escuta individual em horários agendados, em que se espera que a pessoa compareça e, caso isso não ocorra, não há busca ativa, nem investimento em outras formas de escuta.

Com relação ao Caps, há bastante descontinuidade. No momento da crise, os acolhimentos no Caps são bastante resolutivos, a equipe é elogiada, mas ainda há problemas na construção de um PTS que considere as possibilidades e os desafios de cada caso.

A descontinuidade ocorre ligada a fatores como falta de escuta em relação aos efeitos dos medicamentos e falta de vínculo com os profissionais. Este último constitui fator importante para aqueles usuários que, ao sair do momento crítico, após uma melhora, não se encaixam no quadro de crise psicótica, mas estão em sofrimento. Na maioria deles, a descontinuidade no cuidado ocorre após o encaminhamento para a $\mathrm{AB}$, à qual não se vinculam, causando um gap entre a atenção especializada e a $A B$, o que indica falha na articulação da rede.

É importante ressaltar o fator ambiente do Caps. A maioria dos entrevistados refere sentir mal-estar no ambiente, que é percebido pelo usuário como não acolhedor, ameaçador, perturbador, desorganizado, abandonado, malcuidado. Essa percepção negativa do ambiente é relatada em relação não só à aparência do ambiente físico, mas também ao fato de haver pessoas em estado de sofrimento agudo, com quadro de crises e de uso de substâncias. $\mathrm{Na}$ visão dos entrevistados, essas pessoas estão dopadas, ou contidas fisicamente, ou sem a devida atenção. Para os usuários que têm uma crítica em relação a esse ambiente, fica inviável permanecer nele por mais tempo, embora às vezes ainda necessitem do tratamento.

Por fim, no que tange às internações psiquiátricas em hospitais, prevaleceram as abordagens médico-centradas e com foco na medicação.

Concluímos que, nos casos estudados, o abandono do tratamento ocorre principalmente após a estabilização da crise aguda e no encaminhamento para a $\mathrm{AB}$, incrementado pelos problemas no PTS e falhas na articulação da rede, principalmente no que tange à continuidade do acompanhamento psicológico.

\section{Colaboradoras}

Bandeira N (0000-0003-4391-5414)* contribuiu para a concepção, planejamento, análise e interpretação dos dados, elaboração do rascunho, revisão crítica do conteúdo e aprovação da versão final do manuscrito. Onocko-Campos R (0000-0003-0469-5447)* contribuiu para a concepção e delineamento da pesquisa, análise e interpretação dos dados, revisão crítica e aprovação da versão final do manuscrito.
Orcid (Open Researcher and Contributor ID) 


\section{Referências}

1. Organización Mundial de la Salud. Plan de acción sobre Salud Mental 2013-2020 [internet]. Ginebra: OMS; 2013. Disponível em: https://www.who.int/ mental_health/publications/action_plan/es/.

2. Organización Panamericana de la Salud. World Mental Health Day 2020 [internet]. 2020 [acesso em 2020 out 17]. Disponível em: https://www.paho.org/en/ campaigns/world-mental-health-day-2020.

3. World Health Organization. Global Health Observatory data [internet]. 2018 [acesso em 2020 out 17]. Disponível em: https://www.who.int/data/gho/data/ themes/mental-health.

4. Health M, Action G. Mental Health Gap Action Programme: Scaling up care for mental, neurological, and substance use disorders [internet]. 2008. [acesso em 2020 out 17]. Disponível em: http://www.who. int/mental_health/evidence/mhGAP/en/.

5. Chatterjee S, Leese M, Koschorke M, et al. Collaborative community based care for people and their families living with schizophrenia in India: protocol for a randomised controlled trial. Trials [internet]. 2011 [acesso em 2018 maio 20]; 12(1):12. Disponível em: http://trialsjournal.biomedcentral.com/ articles/10.1186/1745-6215-12-12.

6. Lora A. An overview of the mental health system in Italy. Ann Ist Super Sanita [internet]. 2009 [acesso em 2018 maio 20]; 45(1):5-16. Disponível: http://www. ncbi.nlm.nih.gov/pubmed/19567972.

7. Fekadu A, Thornicroft G. Global mental health: perspectives from Ethiopia. Glob Health Action [internet]. 2014 [acesso em 2018 maio 20]; 7(1):25447. Disponível em: https://www.tandfonline.com/doi/full/10.3402/gha.v7.25447.

8. Kohn R, Ali AA, Puac-Polanco V, et al. Mental health in the Americas: an overview of the treatment gap. Rev Panam Salud Pública. 2018; (42):1-10.

9. Oliveira GL, Waleska Teixeira C, Cherchiglia ML. Saúde mental e a continuidade do cuidado em cen- tros de saúde de Belo Horizonte, MG. Rev Saude Publica [internet]. 2008 [acesso em 2018 maio 20]; 42(4):707-16. Disponível em: http://www.scielo.br/scielo.php?script=sci_arttext\&pid=S0034$-89102008000400018 \&$ lang=pt.

10. Rodriguez J. Los servicios de salud mental en América Latina y el Caribe: la evolución hacia un modelo comunitario. Rev Psiquiatr Urug [internet]. 2011 [acesso em 2018 maio 20]; 75(2):86-96. Disponível em: http://www.spu.org.uy/revista/dic2011/03_rodriguez.pdf.

11. Borysow IC, Furtado JP. Access, equity and social cohesion: Evaluation of intersectoral strategies for people experiencing homelessness. Rev da Esc Enferm. 2014; 48(6):1066-73.

12. Araujo AK, Tanaka OY. Avaliação do processo de acolhimento em Saúde Mental na região centro-oeste do município de São Paulo: a relação entre CAPS e UBS em análise. Interface - Comun Saúde, Educ [internet]. 2012 [acesso em 2018 maio 20]; 16(43):917-28. Disponível em: http://www.scielo.br/scielo.php?script=sci arttext\&pid=S1414-32832012000400005\&lng=pt\&n $\mathrm{rm}=\mathrm{iso} \& \mathrm{tlng}=\mathrm{en}$.

13. Oliveira RF, Andrade LOM, Goya N. Acesso e integralidade: a compreensão dos usuários de uma rede de saúde mental. Ciênc. Saúde Colet. [internet]. 2012 [acesso em 2018 maio 20]; 17(11):3069-78. Disponível em: http://www.scielo.br/scielo.php?script=sci_ arttext\&pid=S1413-8123012001100023\&lng=pt\&tln $\mathrm{g}=\mathrm{pt}$.

14. Delgado PG. Limites para a inovação e pesquisa na reforma psiquiátrica. Physis. 2015; 25(1):13-8.

15. Onocko-Campos RT. Mental health in Brazil: strides, setbacks, and challenges. Cad. Saúde Pública [internet]. 2019 [acesso em 2021 mar 22]; 35(11):e00156119. Disponível em: http://www.scielo.br/scielo.php?script=sci_arttext $\&$ pid $=$ S0102$-311 X 2019001300501 \& \operatorname{lng}=\mathrm{en}$. 
16. Brasil. Ministério da Saúde. Saúde Mental em Dados - 12 [internet]. 2015 [acesso em 2018 maio 20]. Disponível em: http://portalsaude.saude.gov.br/index.php/o-ministerio/principal/secretarias/801-sas-raiz/daet-raiz/saude-mental/20309-saude-mental-em-dados-12-edicao.

17. Onocko-Campos RT, Amaral CEM, Saraceno B, et al. Atuação dos Centros de Atenção Psicossocial em quatro centros urbanos no Brasil. Rev Panam Salud Pública. 2018; (42):1-7.

18. Brasil. Ministério da Saúde. Portaria n ${ }^{\circ} 3.588$, de 21 de dezembro de 2017. [internet]. 2017 [acesso em 2018 maio 20]. Disponível em: http://bvsms.saude.gov.br/ bvs/saudelegis/gm/2017/prt3588_22_12_2017.html.

19. Brasil. Ministério da Saúde. Nota Técnica no 11/2019-CGMAD/DAPES/SAS/MS [internet]. Brasília, DF; 2019. Disponível em: http://mds.gov.br/ obid/nova-politica-nacional-de-saude-mental.

20. Almeida JMC. Mental health policy in Brazil: What's at stake in the changes currently under way. Cad. Saúde Pública. 2019; 35(11).

21. Mnookin S. Out of the shadows : making mental health a global development priority (English). Washington, D.C.: World Bank Group. 2016. [acesso em 2021 mar 31]. Disponível em: http://documents.worldbank.org/curated/en/270131468187759113/Out-of-the-shadows-making-mental-health-a-global-development-priority.

22. Sweetland AC, Oquendo MA, Sidat M, et al. Closing the mental health gap in low-income settings by building research capacity: perspectives from Mozambique. Ann Glob Heal [internet]. 2014 [acesso em 2018 maio 20]; 80(2):126-33. Disponível em: http://inkinghub.elsevier.com/retrieve/pii/S2214999614000526.
23. Mângia EF, Yasutaki PM. Itinerários terapêuticos e novos serviços de saúde mental. Rev Ter ocup Univ. 2008; 19(1):61-71.

24. Silva VMN, Silva-Junior AG, Pinheiro R, et al. Trajetória assistencial em Piraí : uma prática avaliativa amistosa à integralidade. In: Pinheiro R, Silva-Junior AG, Mattos RA, organizadores. Atenção Básica e integralidade: contribuições para estudos de práticas avaliativas em saúde. Rio de Janeiro: Cepesc; IMS; UERJ; ABRASCO; 2008. p. 225-32.

25. Onocko-Campos RT, Campos GWS, Ferrer AL, et al. Avaliação de estratégias inovadoras na organização da Atenção Primária à Saude. Rev Saúde Pública [internet]. 2012 [acesso em 2018 maio 20]; 46(1):43-50. Disponível em: www.scielo.br/rsp.

26. Campos RO, Belo KO, Trapé TL, et al. O PET-saúde como instrumento para a articulação da saúde mental e coletiva : narrativas da formação e do trabalho em saúde. Cad Bras Saúde Ment. 2012; 4(8):176-85.

27. Onocko-Campos RT, Gama CAP. Saúde mental na Atenção Básica. In: Campos GWS, Guerrero AVP, organizadores. Manual de Práticas de Atenção Básica: saúde ampliada e compartilhada. 3. ed. São Paulo: Hucitec; 2013. p. 221-46.

Recebido em 22/11/2019

Aprovado em 19/10/2020

Conflito de interesses: inexistente

Suporte financeiro: 405044-3 - Chamada MCTI/CNPq/MS -

SCTIE - Decit № 41/2013 - Rede Nacional de Pesquisas sobre Política de Saúde: Conhecimento para Efetivação do Direito

Universal à Saúde. Além do CNPq, a pesquisa teve apoio da Fundação de Amparo à Pesquisa do Estado de Mato Grosso (Fapemat) através da bolsa de doutorado, concedida por meio do edital no 009/2016 